\title{
EL DERECHO DE CASA-HABITACIÓN. EL ENFRENTAMIENTO ENTRE LOS MAESTROS Y EL AYUNTAMIENTO DE ZARAGOZA DURANTE LA SEGUNDA REPÚBLICA
}

\author{
The right to house room. \\ The confrontation between teachers and the city council \\ of Zaragoza during the Second Republic
}

\section{Héctor Vicente Sánchez ${ }^{\&}$}

Fecha de recepción: 31/08/2017 • Fecha de aceptación: 07/03/2018

Resumen. La ley educativa de 9 de septiembre de 1857, comúnmente conocida como ley Moyano, concedía el derecho de casa-habitación a los maestros. Desde esa fecha, hasta la proclamación de la Segunda República, se sucederían un buen número de preceptos legislativos que lejos de aclarar como debía ser el disfrute del citado derecho tendió a crear confusión. La instauración del régimen republicano traería consigo nuevas disposiciones legales que contribuirían a perpetuar una tradición legislativa contradictoria. Fue dentro de este marco legal, extenso a la par que confuso, en el que entablaron su particular batalla los maestros de Zaragoza y la corporación municipal de la ciudad. Desde los primeros compases del quinquenio republicano los maestros consortes y los de los barrios, principalmente, harían llegar sus reclamaciones al cabildo. Este a su vez trató de hacer valer sus intereses contra un derecho que venía obligado a sufragar y que suponía un desembolso importante. La reforma educativa emprendida a partir de abril de 1931 no haría sino agravar el problema. La creación de nuevos centros educativos y la sustitución de la enseñanza religiosa provocaron la necesidad de aumentar la partida económica para satisfacer esta atención. Ante esta coyuntura los ediles zaragozanos trataron de buscar soluciones más económicas para hacer frente a esta obligación que venía obligado a sufragar.

Palabras clave: Segunda República española; Educación; Legislación; Casa-habitación.

\footnotetext{
\& Departamento de Historia Moderna y Contemporánea. Facultad de Filosofía y Letras. Universidad de Zaragoza. C/ Pedro Cerbuna, 12. 50009 Zaragoza. España. hectorvicentes@gmail.com
}

Cómo citar este artículo: Inarejos Muñoz, Juan Antonio. «La enseñanza de la Historia en las Filipinas españolas a través de los libros de texto: negocio, censura y control social». Historia y Memoria de la Educación 9 (2019): 443-472. 
Abstract. The education law of the 9th of September 1857, commonly known as Moyano's law, granted the right to a house-room for teachers. From this date until the proclamation of the Second Republic, despite the many legal precepts enacted, the enjoyment of this right was not clarified. The establishment of the republican regime brought new legal dispositions, but the conflicting legislation persisted. Within this large and confusing legal framework, teachers in Zaragoza did battle with the municipal corporation starting at the beginning of the republican period. The city council tried to avoid costs related to this right which implied a significant disbursement, and the educational reform initiated in April 1931 only aggravated the problem. The creation of new education centres and the replacement of religious education increased costs for this right. Against this background, councillors tried to find economic solutions for covering this mandatory cost.

Keywords: Spanish Second Republic; Education; Legislation; Houseroom.

\section{INTRODUCCIÓN}

El trabajo que a continuación vamos a desarrollar tiene como objetivo analizar como fue la evolución legislativa del derecho de los maestros al disfrute de casa-habitación y el enfrentamiento que se produjo entre el Ayuntamiento de Zaragoza y los maestros de la ciudad por su concesión. Para desarrollar este planteamiento hemos dividido la investigación en dos grandes apartados. El primero lo hemos dedicado al análisis de la legislación promulgada desde la concesión del derecho en 1857 hasta la proclamación del régimen republicano. La segunda parte está centrada en los diferentes conflictos surgidos entre el cabildo zaragozano y los maestros de la localidad al tiempo que abordamos la legislación que sobre la materia fueron aprobando los diversos gabinetes republicanos.

Para llevar a cabo esta labor hemos tenido que recurrir principalmente a fuentes hemerográficas y archivísticas, pues apenas hay referencias bibliográficas que hayan abordado esta cuestión en profundidad. ${ }^{1}$ Para abordar las cuestiones legislativas de la primera parte del

\footnotetext{
${ }^{1}$ El único trabajo centrado en el derecho a casa-habitación es el de Jesús González Pérez, «La indemnización por casa-habitación y la contribución de utilidades», Revista de administración pública 18 (1955): 207-220. Pero el marco cronológico que aborda es posterior al que este trabajo analiza.
} 
trabajo hemos recurrido al uso de la Gaceta de Madrid y a la obra de Victoriano Fernández Ascarza. ${ }^{2}$ Para la segunda parte hemos vuelto a recurrir a la consulta de la Gaceta de Madrid, pero principalmente nos hemos basado en la información aportada por las fuentes archivísticas y hemerográficas. Como complemento hemos incluido alguna referencia bibliográfica que nos ha permitido aclarar algunos de los temas abordados.

\section{7-1931. EVOLUCIÓN LEGISLATIVA DEL DERECHO DE CASA- HABITACIÓN}

El origen del derecho de los maestros a percibir casa-habitación debemos situarlo en el artículo 191 de la ley de Instrucción Pública de 9 de septiembre de 1857. En él quedaba regulado el sueldo fijo que debían percibir los maestros de las escuelas públicas elementales. La retribución de los docentes quedaba complementada con el derecho a disfrutar de casa decente y capaz para él y su familia, ${ }^{3}$ siendo responsabilidad de los ayuntamientos el pago de esta atención. ${ }^{4}$ La interpretación del artículo 191 fue el origen de una larga serie de Órdenes, Decretos, Reales órdenes y Reales decretos que variaron la forma de concesión de este derecho, sobre todo en lo referente a los maestros consortes.

La primera regulación que afectó a los maestros consortes fue la Orden de 13 de junio de 1870 por la que la Dirección General de Instrucción Pública limitó al disfrute de una sola casa a los maestros que estuvieran casados y residieran en la misma población. ${ }^{5}$ Esta disposición estuvo vigente hasta octubre de 1894 cuando un grupo de maestros de

\footnotetext{
${ }^{2}$ Victoriano Fernández Ascarza, Diccionario de legislación de primera enseñanza (Madrid: Magisterio Español, 1924).

${ }^{3}$ Ley de Instrucción pública de 9 de mayo de 1857, autorizada por el Gobierno para que rija desde su publicación en la Península e Islas adyacentes, lo que se cita, Gaceta de Madrid (en adelante G.M.) 1710, 10 de septiembre de 1857.

${ }^{4}$ Real Decreto de 26 de octubre de 1901, autorizando al Ministro de Instrucción pública y Bellas Artes para que en los presupuestos generales de su departamento, á partir del que se forme para el año 1902, incluya las partidas necesarias, conforme a las disposiciones de este decreto, para el pago de las atenciones de personal y material de las Escuelas públicas de primera enseñanza, G.M. 303, 30 de octubre de 1901.

${ }^{5}$ Fernández Escarza, Diccionario de legislación, 154.
} 
las escuelas públicas pidieron su derogación, consiguiendo que el artículo 191 no fuera interpretado de manera restrictiva y cada maestro pudiera disfrutar de casa-habitación independientemente de su estado civil. ${ }^{6}$ En el mismo sentido de no poner limitaciones estaba redactada la Orden de 9 de agosto de 1899 que exponía que cuando un maestro y una maestra de la misma localidad fueran esposos, cada uno tendría derecho a casa-habitación o al percibo de un alquiler si el ayuntamiento lo hubiese concertado así. ${ }^{7}$ Como garantía para los maestros, el Real decreto de 8 de junio de 1910 fijaba para los casos en los que los ayuntamientos no abonaran a los maestros las cantidades acoradas, la posibilidad de que el Estado las incautara y las abonara directamente a los maestros. ${ }^{8}$

Sin embargo la interpretación restrictiva de este derecho volvió a imponerse por medio de la Real orden de 22 de junio de 1910 cuando, ante una reclamación de los maestros de Fuentes de Ropel, fue dictaminado que los maestros consortes que vivieran en el mismo pueblo sólo disfrutarían de una casa. ${ }^{9}$ Esta limitación de los derechos de los maestros consortes provocó que fueran interpuestas un buen número de reclamaciones mostrando su oposición a la nueva legislación. En junio de 1911, una Real orden procedió a derogar las Reales órdenes de junio de 1870 y junio de 1910 al tiempo que decretaba que la interpretación que debía hacerse del artículo 191 era la observada en la Real orden de octubre de $1894 .{ }^{10}$

Este reconocimiento a favor de los maestros fue efímero puesto que el Real decreto de septiembre de 1913 sobre la subsistencia del cargo de Delegado Regio de primera enseñanza, sirvió para puntualizar, en su artículo 27, que los maestros consortes no tendrían derecho a disfru-

\footnotetext{
${ }^{6}$ Real orden de 29 de octubre de 1894, solicitando la derogación de la Dirección general de Instrucción pública de 13 de junio de 1870, por parte de los Maestros que se citan, G.M. 333, 29 de noviembre de 1894.

${ }^{7}$ Fernández Escarza, Diccionario de legislación, 154.

${ }^{8}$ Real Decreto de 8 de junio de 1910, sobre reorganización de la Escuelas de primera enseñanza, G.M. 162, 11 de junio de 1910 .

${ }_{9}^{9}$ Fernández Escarza, Diccionario de legislación, 154.

${ }^{10}$ Real Orden de 30 de junio de 1911, resolviendo reclamaciones producidas contra la de 22 de junio de 1910, que derogó la de 29 de octubre de 1894, por la que se definió el derecho a ocupar casa-habitación de los Maestros consortes que se sirvieran en la misma localidad, G.M. 203, 22 de julio de 1911.
} 
tar por el indicado concepto más que una sola indemnización. ${ }^{11}$ Con la legislación favoreciendo nuevamente los intereses de las instituciones, el Ayuntamiento de Madrid consiguió que fuera firmada una Real orden, el primero de diciembre de 1914, en la que a los maestros consortes sólo se les reconocía el derecho a disfrutar de una casa-habitación. ${ }^{12}$ Posteriormente el Gobierno matizó que los maestros y maestras que obtuvieran la escuela por el derecho de consortes no podrían disfrutar del derecho de casa-habitación. ${ }^{13}$ Esta Real orden sirvió para que los ayuntamientos de Soria y Cazorla dejaran de abonar la cuantía que venían abonando por casa-habitación a algunos de sus maestros. Pero ambos ayuntamientos fueron conminados a abonar los haberes atrasados puesto que la referida norma sólo podía aplicarse desde el momento de su publicación, debiendo continuar abonando la indemnización a quienes ya la percibían. ${ }^{14}$

Las disputas entre maestros e instituciones terminaron ante los tribunales en muchas ocasiones, y a lo largo de 1917 llegaron dos sentencias importantes. La primera motivó una Real orden de 24 de marzo que resolvió el recurso contencioso-administrativo interpuesto por un grupo de maestros consortes contra la Real orden de 1 de diciembre de 1914. El fallo del Tribunal dictaminaba que el artículo 191 de la ley de septiembre de 1857 no permitía privar al maestro que se casara con maestra, o viceversa, de derecho de casa o indemnización por ella. ${ }^{15}$ Sin embargo, la resolución del recurso interpuesto contra la Real orden de 16 de julio de 1916 interpretó que la ley de 1857 establecía el dere-

\footnotetext{
${ }^{11}$ Real Decreto de 16 de septiembre de 1913, disponiendo quede subsistente el cargo de Delegado Regio de primera enseñanza, creado por el de 14 de Septiembre de 1902, con las atribuciones y deberes que se determinan en los artículos que se mencionan, G.M. 264, 21 de septiembre de 1913.

12 Fernández Escarza, Diccionario de legislación, 154.

${ }^{13}$ Real Orden de 16 de julio de 1916, dictando reglas para la recta aplicación del Real Decreto de 10 del actual, G.M. 206, 24 de julio de 1916.

${ }^{14}$ Orden de 12 de octubre de 1916, declarando que el Ayuntamiento de Soria viene obligado a abonar a la Maestra la indemnización de 22,50 pesetas para casa habitación, G.M. 295, 19 de octubre de 1916 y Orden de 27 de octubre de 1916, resolviendo instancia de D. Pedro Muñoz Rodríguez, Maestro de Cazorla, solicitando que por el Ayuntamiento de la localidad referida se le abone la indemnización que para casa habitación le tiene asignada, G.M. 608, 3 de noviembre de 1916.

${ }^{15}$ Real orden de 24 de marzo de 1917, disponiendo se cumpla en sus propios términos la sentencia dictada por la Sala de lo Contencioso Administrativo del Tribunal Supremo en recurso interpuesto por D. Manuel Martín Tamayo y otros, contra la Real orden dictada por este Ministerio en $1 .^{\circ}$ de diciembre de 1914, G.M. 106, 16 de abril de 1917.
} 
cho del maestro a casa-habitación, y que nada se decía sobre la obligación de suministrar dos casas a los maestros consortes residentes en la misma localidad. ${ }^{16}$

Ante la prolijidad legislativa sobre este derecho y la falta de un criterio unánime sobre como debía concederse, fue redactado el Real decreto de 28 de febrero de 1919. Con arreglo a lo dispuesto en el artículo 191 de la ley de 9 de septiembre de 1857, los maestros y maestras de las Escuelas Nacionales de Primera enseñanza tendrían derecho a disfrutar de habitación capaz y decente para ellos y sus familias. Correspondería este derecho a todos los maestros, ya fueran directores de graduadas o auxiliares. La responsabilidad de proporcionar a los maestros la habitación recaía sobre los ayuntamientos de la localidad donde estuviera situada la escuela en la cual prestaban los servicios. Los maestros y el cabildo, de común acuerdo, decidirían si las viviendas proporcionadas reunían las condiciones de capacidad y decencia exigidas. En caso de disparidad, la Inspección de Primera enseñanza informaría a la Dirección general y resolvería lo que estimara oportuno. Esta resolución supondría la aprobación o desaprobación de la vivienda ofrecida. En caso de no ser aceptada, el Municipio tendría quince días para proporcionar una nueva o, en su defecto, abonar al maestro una indemnización anual que sería fijada por la Dirección General de Primera enseñanza. Así mismo los ayuntamientos podrían, en todo caso, sustituir la obligación de proporcionar casa a los maestros por el abono de una indemnización equivalente, fijada de acuerdo con aquellos o sometiéndose al dictamen de la Inspección de Primera enseñanza. En ningún caso los ayuntamientos podrían reducir las indemnizaciones que tuvieran establecidas con anterioridad a la publicación del decreto. Si la casa ofrecida por el Ayuntamiento no fuera de propiedad municipal, se reconocía a los maestros el derecho de optar entre su disfrute o el de una indemnización equivalente al importe de los alquileres que el municipio satisficiera. A los maestros y maestras sustitutos e interinos también les fue reconocido el derecho al disfrute de casa-habitación o a la indemnización equivalente. El artículo décimo reconocía que el derecho de casa-habitación era inherente a la condición de maestro nacional; por lo tanto, los maestros consortes conservaban el derecho de disfrutar de las

\footnotetext{
${ }^{16}$ Fernández Escarza, Diccionario de legislación, 155.
} 
habitaciones correspondientes a ambos. Al mismo tiempo, reconocía a los ayuntamientos la facultad de sustituir este derecho por una indemnización equivalente a los dos tercios de la cantidad que, de no tener la condición de consortes, les correspondería con arreglo a las prescripciones de este decreto. ${ }^{17}$ Con la Orden de 18 de marzo de 1919 quedó matizado que en caso de que los ayuntamientos no dispusieran de locales propios que reunieran las condiciones necesarias para hogar de los maestros, estos podrían optar entre una casa, que a juicio de los inspectores reuniera los requisitos legales, proporcionada por el municipio, o a una indemnización en metálico. ${ }^{18}$

A pesar de la existencia de una profusa legislación entorno al alojamiento de los maestros había un aspecto que todavía no se había regulado: la cuantía que los ayuntamientos debían satisfacer a los profesores en caso de no poder suministrarles casa decente y capaz. Fue con la promulgación del Estatuto General del Magisterio de Primera Enseñanza cuando se fijó por primera vez la escala de las cuantías a satisfacer:

$\begin{array}{lr}\text { Poblaciones menores de } 500 \text { habitantes } & 100 \text { pesetas. } \\ \text { De } 501 \text { a } .1 .000 \text { habitantes } & 150 \text { pesetas. } \\ \text { De } 1.001 \text { a } 5.000 \text { habitantes } & 250 \text { pesetas. } \\ \text { De } 5.001 \text { a } 10.000 \text { habitantes } & 500 \text { pesetas. } \\ \text { De } 10.001 \text { a } 20.000 \text { habitantes } & 750 \text { pesetas. } \\ \text { De } 20.001 \text { a } 40.000 \text { habitantes } & 1.000 \text { pesetas. } \\ \text { De } 40.001 \text { a } 100.000 \text { habitantes } & 1.250 \text { pesetas. } \\ \text { De } 100.001 \text { a } 500.000 \text { habitantes } & 1.500 \text { pesetas. } \\ \text { Madrid y Barcelona } & 2.000 \text { pesetas. }\end{array}$

Los redactores del Estatuto volvieron a introducir novedades con respecto a la última legislación de marzo de 1919. Los maestros cónyuges que residieran en la misma población solo disfrutarían de una sola casa-habitación o de una sola indemnización en su caso. ${ }^{19}$ Tres meses

\footnotetext{
17 Real Decreto de 28 de febrero de 1919, disponiendo que todos los Maestros, ya sean unitarios, Directores de graduadas, Auxiliares, etc., disfruten de casa-habitación capaz para ellos y su familia, G.M. 61, 2 de marzo de 1919.

18 Fernández Escarza, Diccionario de legislación, 155.

${ }^{19}$ Real Decreto de 18 de mayo de 1923, aprobando el Estatuto general del Magisterio de Primera enseñanza, que se inserta, G.M. 139, 19 de mayo de 1923.
} 
después, una Real orden matizaba que aquellos maestros que estuvieran en posesión de los emolumentos legales concedidos con anterioridad al Estatuto, procedía que los siguieran disfrutando en tanto no variara su condición profesional. ${ }^{20}$

Durante el periodo dictatorial de Miguel Primo de Rivera no fueron introducidas modificaciones en el Estatuto general del Magisterio de Primera enseñanza, algo que si ocurrió tras su caída. Con Dámaso Berenguer en el poder, fue promulgado el Real decreto de 5 de febrero de 1931 que sirvió para introducir modificaciones en el Estatuto de Magisterio. El artículo 15, relativo a la concesión de casa-habitación, fue uno de los que fueron modificados a favor de los intereses de los maestros. Si desde mayo de 1923 los maestros sólo habían tenido derecho a una casa o una indemnización, a partir de febrero de 1931 tendrían derecho a una casa y una indemnización por la casa que no necesitaban o a dos indemnizaciones. ${ }^{21}$ Poco más de un mes después volvieron a introducirse nuevas modificaciones. La situación de inestabilidad que sufría el país provocó la caída de Dámaso Berenguer y el ascenso al poder del Almirante Aznar el 18 de febrero de 1931. El nuevo Ministro de Instrucción Pública y Bellas Artes, José Gascón y Marín, dejó en suspenso los Reales decretos que habían modificado el Estatuto general del Magisterio de Primera enseñanza, volviendo a dejar en vigor el texto original de 1923. Nuevamente los maestros pasaban a disfrutar sólo de una casa o una indemnización. ${ }^{22}$ Era marzo de 1931, y un mes después José Gascón y Marín, el Almirante Juan Bautista Aznar y el propio régimen monárquico dejaron paso al recién nacido Gobierno republicano.

\footnotetext{
${ }^{20}$ Real Orden de 10 de agosto de 1923, relativa a la significación y alcance de la regla primera de la Real Orden de 26 de Mayo último, en la que se relaciona con los derechos personales adquiridos al amparo de la legislación vigente, G.M. 705, 14 de agosto de 1923.

${ }^{21}$ Real Decreto de 5 de febrero de 1931, derogando el texto del Capítulo quinto del Estatuto general del Magisterio primario, y aprobando, en sustitución, el nuevo y adjunto texto del mismo, G.M. 376 de febrero de 1931 .

${ }_{22}$ Real Decreto de 7 de marzo de 1931, ratificando la Real Orden de 5 del corriente, acortada en Consejo de Ministros, dejando en suspenso la aplicación y efectividad de los Reales decretos de 25 de Octubre y de 14 de Noviembre de 1930 y de 5 de Febrero pasado, hasta que se publique un texto refundido del Estatuto general del Magisterio, G.M. 70, 11 de marzo de 1931.
} 


\section{1-1936. LA SEGUNDA REPÚBLICA. UN PERIODO DE CONFLICTOS Y DE BÚSQUEDA DE SOLUCIONES}

Cuando las nuevas autoridades republicanas accedieron al poder, el magisterio español arrastraba décadas de insatisfacciones y agravios. Sus condiciones laborales y económicas eran pésimas, lo que había provocado que las asociaciones que agrupaban al magisterio español centraran sus debates en torno a dos cuestiones prioritarias: la problemática salarial y la búsqueda de mecanismos que les permitiesen la organización y la representación nacional del magisterio. En el plano económico habían conseguido alguna mejora desde que en 1902 los salarios de los profesares dejaron de ser competencia municipal y pasaron a serlo del Estado. Los primeros gobiernos republicanos buscaron hacer frente a estas cuestiones involucrando a las asociaciones de maestros para que colaboraran en el Consejo de Instrucción Pública en la elaboración de la nueva Ley de Instrucción Pública, o formando parte de la Comisión encargada de reformar el Estatuto del Magisterio. En el apartado económico también introdujeron mejoras como el incremento del sueldo de los maestros situados en las categorías inferiores. Las nuevas autoridades tampoco podían obviar otra cuestión que durante largas décadas había suscitado las reclamaciones de los maestros como era lo concerniente a su alojamiento o la indemnización sustitutoria a percibir. ${ }^{23}$

No puede decirse que los diferentes gabinetes ministeriales republicanos se prodigaran mucho legislando sobre el derecho de casa-habitación; no obstante, cuando lo hicieron tuvo importantes repercusiones. Como veremos en el primer bienio la atención estuvo centrada en los maestros de los barrios rurales, siendo los maestros consortes sobre los que se centró la polémica en el segundo bienio. El Ayuntamiento de Zaragoza tuvo que ir adaptándose a las diversas disposiciones gubernamentales, al tiempo que buscó las soluciones más óptimas para conciliar los derechos de los maestros con sus propios intereses.

\footnotetext{
${ }^{23}$ Aida Terrón, «El movimiento asociacionista del magisterio nacional: orígenes y configuración histórica», Historia de la educación. Revista interuniversitaria 6 (1987): 279-300, y «Cien años de defensa colectiva: la dinámica societaria y sindical del magisterio español», Sarmiento. Anuario galego de historia da educación 3 (1999): 157-182.
} 


\section{Un primer bienio de calma relativa}

En sus primeros días de actuación, el Gobierno provisional fijó su postura con respecto a los derechos de los maestros consortes de forma clara. Una Orden de 27 de abril estableció que tenían derecho a percibir dos indemnizaciones, o una casa y una indemnización, los maestros consortes que residían en la misma localidad y que, como solteros, disfrutaban de dos habitaciones. La regulación contenida en esta Orden fue la base para resolver el expediente incoado por un grupo de maestros nacionales consortes de Madrid contra el acuerdo adoptado por la Junta municipal de Primera enseñanza. Este organismo dictaminó que los maestros consortes solo disfrutaran de una casa-habitación, acuerdo que fue declarado nulo por el Ministerio que reconoció el derecho de los maestros al disfrute de dos viviendas. ${ }^{24}$

Los maestros consortes de Zaragoza sí que vieron garantizado su derecho a percibir, como el resto de maestros no consortes, el doble emolumento por casa-habitación desde abril de 1932 hasta que el Ayuntamiento pudiera facilitarles una vivienda digna. En la misma sesión del 25 de marzo de 1932, los representantes municipales tuvieron que afrontar los cambios legislativos introducidos por medio de la Orden de 20 de julio de 1931, que afectaban a los maestros que desempeñaban su actividad en escuelas enclavadas en entidades de población pertenecientes a grandes municipios. ${ }^{25}$ Durante la primera estancia de Marcelino Domingo al frente del Ministerio de Instrucción Pública y Bellas Artes el Consejo de Instrucción Pública resolvió que los emolumentos que percibían los maestros que desarrollaban su actividad en los barrios aledaños debían equipararse a los de la capital. ${ }^{26}$ Acogiéndose a esta Orden ministerial los maestros de los barrios rurales de Montemolín, Casetas, Villamayor, Monzalbarba, San Juan de Mozarrifar, Montañana, Miralbueno, Movera, Juslibol, Garrapinillos, El Castillo y la Cartuja Baja

\footnotetext{
${ }^{24}$ Orden de 16 de julio de 1931, resolviendo el expediente incoado con motivo del recurso interpuesto por varios Maestros Nacionales, consortes, de Madrid, contra el acuerdo de la Junta municipal de Primera enseñanza que dio de baja en nómina a todo Maestro o Maestra cuyo cónyuge disfruta de casa-habitación o percibe indemnización por tal concepto, G.M. 206, 25 de julio de 1931.

25 «Actas del Ayuntamiento de Zaragoza», 25 de marzo de 1932, Archivo Municipal de Zaragoza (A.M.Z.).

${ }^{26}$ Orden de 20 de julio de 1931, revolviendo moción del Consejo de Instrucción pública relativa a emolumentos de Maestros, G.M. 211, 30 de julio de 1931.
} 
solicitaron disfrutar del mismo derecho a casa-habitación y demás emolumentos que sus homólogos de la capital zaragozana, siéndoles aceptada esta demanda por el Consejo de Instrucción Pública. ${ }^{27}$ La postura municipal ante esta demanda fue, con algunos integrantes oponiéndose, entablar un recurso de alzada. ${ }^{28}$ Ante esta resolución, la respuesta de un grupo de maestros de los barrios de Casetas y Monzalbarba fue elevar dos instancias al Ayuntamiento reclamando que fuera incluida, en el siguiente presupuesto municipal, la cantidad necesaria que les correspondía por casa-habitación. ${ }^{29}$

Las desavenencias entre el Ayuntamiento y los educadores continuaron con motivo de la aprobación de los presupuestos municipales. Una vez publicadas las cuentas del consistorio, hasta la Delegación de Hacienda llegaron las reclamaciones de las maestras Luisa Cortés y Carmen Xicola. Ambas docentes solicitaron acogerse a los beneficios que concedía la Orden de 20 de julio de 1931, pues venían ejerciendo su actividad en las escuelas de los barrios rurales del Lugarico de Cerdán y Cascajo, y posteriormente en las escuelas de los barrios de Villacampa y Buen Pastor donde habían sido trasladadas. Las dos maestras venían percibiendo por el concepto de casa-habitación quinientas pesetas, un tercio de lo que percibían sus compañeras de la capital. ${ }^{30} \mathrm{El}$ maestro de la escuela nacional del barrio de Villamayor también solicitó un aumento en la consignación para vivienda, aunque en este caso fue la propia Delegación provincial de Hacienda la que dejó en suspenso la petición. ${ }^{31}$

${ }^{27}$ Orden de 10 de marzo de 1932, haciendo extensivos los beneficios de la Orden ministerial de 20 de Julio de 1931 a los Maestros de los barrios que se citan, de Zaragoza, G.M. 74, 14 de marzo de 1932.

28 "Actas del Ayuntamiento de Zaragoza», 25 de marzo de 1932, A.M.Z.

${ }_{29}$ «Maestros del B. ${ }^{\circ}$ de Monzalbarba, solicitan inclusión de cantidad en presupuesto para casa-habitación», 1932, Sección de Hacienda, Presupuesto, Caja 2605, expediente 1708, A.M.Z., y «Maestros del B. ${ }^{\circ}$ de Casetas, solicitan inclusión de cantidad en presupuesto para casa habitación», 1932, Sección de Hacienda, presupuesto, caja 2605, expediente 1707, A.M.Z.

30 «Oficio del Delegado de Hacienda pidiendo informes sobre derechos a casa-habitación de las maestras municipales», 1933, Sección de Hacienda, varios, caja 2633, expediente 2036, A.M.Z. Desconocemos si finalmente fue atendida la reclamación de ambas maestras puesto que en el expediente no ha sido incluida la resolución del Delegado de Hacienda.

31 «Oficio del Delegado de Hacienda comunicando resolución dictada en la reclamación de D. Manuel Sancho contra denegación de casa-habitación como maestro del barrio de Villamayor», 1933, Sección de Hacienda, varios, caja 2633, expediente 2173, A.M.Z. 
La aprobación de los presupuestos para el ejercicio económico de 1934 provocó nuevamente que algunos maestros elevaran sus reclamaciones ante la Delegación de Hacienda. Los reclamantes fueron los maestros nacionales de los barrios de Monzalbarba, Casetas y Villamayor, alegando que el Ayuntamiento no había incluido en el presupuesto la cuantía suficiente para el abono de sus haberes por casa-habitación. La respuesta del Delegado de Hacienda fue comunicar al cabildo la posibilidad de que el presupuesto fuera impugnado si no cumplía sus obligaciones con los docentes. Ante las posibles consecuencias derivadas del incumplimiento del mandato del Delegado, el Ayuntamiento decidió modificar la partida destinada a instrucción pública para cumplir con las demandas de los profesores. ${ }^{32}$

Simultáneamente a la aparición de las primeras discrepancias entre el Ayuntamiento y los maestros empezaron a plantearse diferentes iniciativas para solucionar el problema. La primera propuesta municipal estuvo vinculada con otro problema que en aquellos momentos también afectaba a la ciudad: las obras de ensanche. El concejo tuvo que hacerse cargo de la liquidación de la Sociedad Zaragozana de Urbanismo y Construcción, encargada de realizar las citadas obras del ensanche, pasando de este modo a ser de propiedad municipal tanto los terrenos como algunas de las manzanas de edificios ya construidas. ${ }^{33}$ Con el objetivo de aminorar los gastos que le ocasionaba el mantenimiento de los inmuebles, los ediles trataron de buscar una solución lo más rápidamente posible. Y en esta coyuntura, la Comisión de Ensanche fue la que planteó la posibilidad de ofrecer a los maestros que percibían subvención por casa-habitación la posibilidad de habitar las viviendas que todavía no habían sido vendidas. La propuesta que el cabildo trasladó a los maestros incluyó los siguientes términos: el Ayuntamiento se comprometía a destinar la totalidad de la subvención concedida por casa-habitación al pago del importe de la amortización e interés anual de la vivienda a ocupar; por su parte el maestro no vendría obligado a satisfacer anticipo alguno a cuenta del importe de la vivienda; el número

\footnotetext{
32 «Escrito de la Alcaldía interesando abono de jubilaciones», 1934, Sección de Hacienda, varios, caja 2653, expediente 1027, A.M.Z.

${ }^{33}$ La gestación del proyecto de ensanche de Zaragoza, puede verse en Sociedad Zaragozana de Urbanización y Construcción, La Sociedad Zaragozana de Urbanización y construcción y el problema de la vivienda protegida (Zaragoza: Sociedad Zaragozana de Urbanización y Construcción, 1930).
} 
de anualidades vendría determinado por la cantidad a amortizar, pudiendo cada interesado incrementar la entrega mediante el anticipo de cuotas anuales completas; y los maestros que ocuparan una de estas habitaciones podrían acogerse a los beneficios de la ley de casas baratas. De cuenta de los nuevos propietarios sería el importe de los servicios y gastos comunes que se derivaran de la propiedad adquirida. La proposición fue bien acogida por los educadores ya que les permitiría ser propietarios de una vivienda sin tener que realizar un esfuerzo económico importante. Un grupo de maestros, cuyo número no podemos precisar, terminó alojándose en las viviendas ofertadas en la manzana 49. ${ }^{34}$

\section{Un segundo bienio de enfrentamiento y búsqueda de soluciones}

Desde los primeros días del régimen republicano los maestros consortes habían visto reconocido su derecho a percibir doble indemnización por casa-habitación o una casa y una indemnización. La jurisprudencia creada durante los dos primeros años de República estuvo sustentada por casos como el de Juan Manuel Uriarte, maestro de Almorox (Toledo). El Ayuntamiento de la localidad le negaba la indemnización por ser consorte; sin embargo, el Ministerio de Instrucción Pública y Bellas Artes reconoció que sí que tenía derecho a percibir indemnización. $\mathrm{O}$ el de los maestros consortes de las escuelas nacionales de Sevilla que consiguieron que les fuera reconocido el mismo derecho que en el caso anterior..$^{35}$ No obstante, la legislación relativa a esta cuestión volvió a ser modificada por medio de una Orden de primero de agosto de 1934. En ella fue atendida la reclamación entablada por la Corporación de Tejares (Salamanca) contra el acuerdo tomado por el Consejo provincial de Primera enseñanza que le obligaba a abonar dos indemnizaciones o dos casas a los maestros consortes. El Ministerio de

\footnotetext{
34 «Habitaciones para los maestros en la manzana 49 de la Gran Vía», Heraldo de Aragón (Zaragoza), 4 de noviembre de 1932.

35 Orden de 16 de mayo de 1933, resolviendo el expediente que se indica, promovido por el Maestro de Almorox (Toledo), D. Juan Manuel Uriarte Sánchez, G.M. 152 (1.6.1933); Orden de 15 de diciembre de 1933, accediendo a lo solicitado por los Maestros consortes de las Escuelas nacionales de Sevilla, respecto a abono de indemnización por casa-habitación, G.M. 354, 20 de diciembre de 1933; Orden de 15 de diciembre de 1933, resolviendo instancia suscrita por doña Rosalía Vicente y otros Maestros nacionales de Sevilla, G.M. 361, 27 de diciembre de 1933; y Orden de 31 de marzo de 1934, resolviendo reclamaciones relativas a indemnizaciones por casa-habitación de los Maestros consortes de Sevilla, G.M. 105, 15 de abril de 1934.
} 
Instrucción Pública y Bellas Artes, atendiendo a los argumentos expuestos por la corporación tejareña, resolvió que los maestros que residieran en la misma localidad sólo tendrían derecho a percibir una sola casa-habitación o una indemnización. ${ }^{36}$ Amparándose en esta disposición, los ediles zaragozanos aprobaron un dictamen por el cual los maestros consortes que hasta esa fecha venían percibiendo doble subsidio, o subsidio y casa, dejaran de hacerlo; el acuerdo municipal reducía a una sola indemnización o vivienda a cada matrimonio. ${ }^{37}$ El viraje legislativo también sirvió a los munícipes de El Puerto de Santamaría para solucionar el contencioso que mantenían con la maestra Librada Mingorance a la que le negaban el pago de casa-habitación puesto que su marido ya percibía dicho pago. Desde agosto de 1934 la citada maestra perdió todo derecho a percibir esa atención. ${ }^{38}$

La restricción de los derechos de los maestros provocó que llegaran hasta las dependencias gubernamentales un buen número de reclamaciones sustentadas en algunas de las múltiples disposiciones aprobadas a lo largo de los años. Los maestros nacionales consortes de Sevilla invocaban la Real Orden de 10 de agosto de 1923 para poder seguir disfrutando de la doble indemnización, aunque la respuesta ministerial aclaraba que dicha Real orden no había sido dictada para matizar el artículo 15 del Estatuto de 1923 sino la Real orden de 23 de mayo de 1923. Los maestros consortes de Ateca (Zaragoza) interpusieron otro recurso de alzada, pero tras ser analizados los informes emitidos por la Inspección provincial de Primera enseñanza, el Ministerio ratificó la Orden de primero de agosto. Igualmente llegaron consultas como la del Ayuntamiento de Alcoy sobre si debía o no pagar la doble indemnización, recibiendo la confirmación de que solo debía abonar una indemnización. ${ }^{39}$

\footnotetext{
36 Orden de 23 de julio de 1934, declarando que los Maestros consortes solo tendrán derecho, cuando residan en una misma localidad, a una sola casa-habitación o a una indemnización, en su caso, G.M. 213, 1 de agosto de 1934.

37 «Actas del Ayuntamiento de Zaragoza», 10 de agosto de 1934, A.M.Z.

${ }_{38}$ Juan Gómez Fernández, La escuela pública en el Puerto: entre la ilusión y la represión (El Puerto de Santa María (Cádiz): El Boletín, 2015), 52.

${ }^{39}$ Orden de 21 de enero de 1935, desestimando petición de los Maestros nacionales, consortes, de Sevilla, solicitando el disfrute de dos indemnizaciones por concepto de casa-habitación, G.M. 25, 25 de enero de 1935; Orden de 21 de enero de 1935, resolviendo recurso de alzada interpuesto por don Anselmo Ibáñez Sánchez y doña Modesta Marcellán Gargallo, Maestros consortes de las Es-
} 
Hasta las oficinas municipales zaragozanas también llegaron reclamaciones de diversa naturaleza. Crescencio Mingo y Patricia Osete solicitaron la reposición del acuerdo que les denegaba la doble indemnización, pero su solicitud fue rechazada. Desde la Inspección de Primera Enseñanza instaron al Ayuntamiento a que pagara la indemnización que había retirado a la maestra de la escuela del Castillo. En similar situación se encontraba Asunción Villalta a quien la Corporación le había retirado la subvención al considerar que era consorte al trabajar su marido en Santa Isabel. En este caso, el Consejo Escolar de Primera Enseñanza dio la razón a la maestra. En ambos supuestos la Municipalidad interpuso sendos recursos en el Ministerio ante las presiones ejercidas por el Consejo Escolar. ${ }^{40}$

Antes de que la Orden de 1 de agosto cumpliera su primer año de vigencia fue revocada por otra Orden de 6 de mayo de 1935. El Ministerio expuso que mientras el Parlamento no derogara o modificara lo dispuesto en el artículo 191 de la ley de 1857, los maestros tendrían reconocido el derecho a disfrutar de casa-habitación o la indemnización correspondiente. Quedaba especificado de forma concisa que la condición de consorte de otro maestro no eximía al municipio de dicha obligación. ${ }^{41}$ Pocas fechas después de la entrada en vigor de esta Orden, dos grupos de maestros consortes de Zaragoza remitieron sendas instancias al Alcalde. En ellas solicitaban que les fuera reconocido el derecho a percibir, como maestros consortes, la doble indemnización por casa-vivienda o una indemnización y vivienda. Asimismo, pedían que tal derecho les fuera reconocido desde el mes de agosto de 1934, momento en que por acuerdo municipal lo habían dejado de percibir. Ante el nuevo

cuelas Nacionales de Ateca (Zaragoza), G.M. 29, 29 de enero de 1935, y Orden de 21 de enero de 1935, participando al Ayuntamiento de Alcoy que sólo debe abonar una sola indemnización de casa-habitación a los Maestros nacionales consortes que residan en la misma localidad, G.M. 27, 27 de enero de 1935.

40 "Crescencio Mingo y Patricia Osete solicitan reposición acuerdo denegando casa-habitación», 1935, Sección de Gobernación, Enseñanza y cultura, Caja 3392, expediente 230, A.M.Z.; «Consejo de $1 .^{\text {a }}$ enseñanza solicita indemnización a la maestra del Castillo», 1935, Sección de Gobernación, Enseñanza y cultura, Caja 3392, expediente 2021, A.M.Z.; e «Inspección 1. ${ }^{\text {a }}$ Enseñanza transmite orden de pago a Asunción Villalta», 1935, Sección de Gobernación, Enseñanza y cultura, Caja 3392, expediente 197, A.M.Z.

${ }^{41}$ Orden de 29 de abril de 1935, declarando que los Maestros tienen reconocido el derecho a disfrutar casa-vivienda o la indemnización correspondiente, y derogando la Orden de 25 de Julio de 1934, G.M. 126,6 de mayo de 1935. 
marco legislativo los munícipes zaragozanos aprobaron un dictamen concediendo a los maestros consortes la doble indemnización por casa-habitación o poder disfrutar de dos viviendas. Igualmente tuvieron que consignar en el presupuesto la cantidad precisa más los derechos que desde abril de 1935 les correspondían. Sin embargo, en un nuevo dictamen, la corporación propuso que fuera declarado lesivo el acuerdo por el cual les eran concedidas dos subvenciones o dos casas-habitación a los maestros consortes. ${ }^{42}$ Para conseguirlo promovió un recurso contencioso administrativo manifestando que, al adoptar el acuerdo, infringía la doctrina legal. Esta recogía que los ayuntamientos sólo estaban obligados a dar una casa habitación o subvención a los maestros consortes cuando estos viviesen en la misma población. Como consecuencia de satisfacer la doble indemnización, se producían daños en los intereses económicos municipales. Esta situación llevó a maestros y Ayuntamiento a dirimir el pleito ante el Tribunal Contencioso Administrativo. La postura de los maestros era que el acuerdo municipal de 28 de junio de 1935 se cumpliera.

Mientras el Tribunal Contencioso resolvía, los maestros continuaban sus reclamaciones. Dos maestros solicitaron que les fuera abonada la indemnización en vez de concederle la casa, ${ }^{43}$ cuatro pidieron que les fueran satisfechos los atrasos en el pago de esta atención, ${ }^{44}$ y un grupo compuesto por diez docentes solicitaron al Concejo que les compensaran la diferencia entre las mil quinientas pesetas que les correspondía por indemnización y la cuantía que el Ayuntamiento pagaba por el alquiler de la casa, que en casi todos los casos era de trescientas cincuenta pesetas. ${ }^{45}$

\footnotetext{
${ }^{42}$ Ambos acuerdos en «Actas del Ayuntamiento de Zaragoza», 28 de junio y 19 de julio de 1935, A.M.Z.

43 «Maestra de Casetas solicita indemnización por casa-habitación», 1935, Sección de Gobernación, Enseñanza y cultura, caja 3392, expediente 4293, A.M.Z., y «Maestra de Casetas solicita indemnización por casa-habitación», 1935, Sección de Gobernación, Enseñanza y cultura, caja 3392, expediente 4320, A.M.Z.

44 «M. ${ }^{a}$ Jesús Díaz, Maestra, solicita indemnización por casa-habitación», 1935, Sección de Gobernación, Enseñanza y cultura, caja 3392, expediente 4084, A.M.Z.; «Asunción Villalta solicita indemnización por casa-habitación», 1935, Sección de Gobernación, Enseñanza y cultura, caja 3392, expediente 4495, A.M.Z.; «Pedro Tobeñas solicita indemnización por casa-habitación», 1935, Sección de Gobernación, Enseñanza y cultura, caja 3392, expediente 4514, A.M.Z. y «Pilar Mercado solicita abono por casa-habitación», 1935, Sección de Gobernación, Enseñanza y cultura, caja 3392, expediente 4638, A.M.Z.

45 «Clemente Mateo y Ladislao Jiménez recurren por denegación de la subvención por vivienda», 1935, Sección de Gobernación, Enseñanza y cultura, caja 3392, expediente 4534, A.M.Z.; «Lucía
} 
El 28 de febrero de 1936 el Tribunal Contencioso Administrativo hizo público su fallo: revocaba el acuerdo tomado en 28 de junio de 1935 dejándolo sin valor y efecto legal alguno. Únicamente podrían seguir percibiendo la doble indemnización aquellos maestros consortes que vinieran percibiéndola con anterioridad al 18 de mayo de $1923 .{ }^{46}$ Una vez conocida la sentencia la reflexión más sensata de la disputa entablada entre maestros y Ayuntamiento la publicó Heraldo de Aragón. Desde sus páginas puso de relieve que la disputa se debía a un excesivo forcejeo por parte del Municipio por eludir una obligación que, aunque iba en aumento, no era motivo para dejarla desatendida. No era el camino correcto resolver contra los maestros, y más contra los consortes. Porque ellos no eran los responsables del aumento de cargas que se hacía sobre los municipios al incrementar aquellos servicios que se consideraban indispensables. Era evidente que sobre los municipios se cargaban muchas obligaciones que en otros tiempos no tenían o eran más llevaderas. Pero era erróneo el camino de cicaterías adoptado porque no resolvía el problema y en cambio conducía al atropello de derechos que se adquirieron al amparo de la ley y de una manera decorosa. ${ }^{47}$

Los desacuerdos entre el Ayuntamiento y los maestros consortes no concluyeron con esta sentencia. La aprobación del presupuesto para el año 1936 volvió a provocar un buen número de reclamaciones de maestros ante la Delegación de Hacienda. En ellas se solicitaba que fueran

\footnotetext{
Escuder solicita abono por casa-habitación», 1935, Sección de Gobernación, Enseñanza y cultura, caja 3392, expediente 4600, A.M.Z.; «Pilar Iglesias solicita abono por casa-habitación», 1935, Sección de Gobernación, Enseñanza y cultura, caja 3392, expediente 4601, A.M.Z.; «Bernardina Arantegui solicita abono por casa-habitación», 1935, Sección de Gobernación, Enseñanza y cultura, Caja 3392, expediente 4602, A.M.Z.; «Victoriano Sanclemente solicita abono por casa-habitación», 1935, Sección de Gobernación, Enseñanza y cultura, caja 3392, expediente 4603, A.M.Z.; «Catalina Sánchez solicita abono por casa-habitación», 1935, Sección de Gobernación, Enseñanza y cultura, caja 3392, expediente 4604, A.M.Z.; "Manuel Sancho solicita abono por casa-habitación», 1935, Sección de Gobernación, Enseñanza y cultura, caja 3392, expediente 4605, A.M.Z.; «Juan Jiménez solicita abono por casa-habitación», 1935, Sección de Gobernación, Enseñanza y cultura, caja 3392, expediente 4625, A.M.Z.; «Victoriano Sanclemente solicita abono por casa-habitación», 1935, Sección de Gobernación, Enseñanza y cultura, caja 3392, expediente 4637, A.M.Z.; «Juan Alcalde solicita abono por casa-habitación», 1935, Sección de Gobernación, Enseñanza y cultura, Caja 3392, expediente 4672, A.M.Z.; y «Pedro Tobeñas solicita abono por casa-habitación», 1935, Sección de Gobernación, Enseñanza y cultura, caja 3392, expediente 4728, A.M.Z.

46 «Fallo del Contencioso sobre doble indemnización a maestros consortes por casa-habitación», 1936, Sección de Gobernación, Edificios escolares, caja 3410, expediente 2679, A.M.Z.

47 «La casa-habitación de los maestros consortes», Heraldo de Aragón (Zaragoza), 25 de febrero de 1935.
} 
consignadas en el presupuesto las cantidades que les adeudaban por casa-habitación. El Consejo Local de Primera enseñanza también trasladó al cabildo algunas reivindicaciones que hasta ellos habían llegado de diversos docentes. Hasta nueve maestros trasladaron al Delegado de Hacienda sus protestas al no ser incluidas en el presupuesto de 1936 las cantidades que todavía les faltaba por percibir. Estas fueron desde las 383,33 pesetas que debían abonarse a la maestra Ascensión Villaba hasta las 2.005 pesetas a Pedro Tobeñas. Todas estas demandas fueron aceptadas a trámite e informando el Consistorio, quien en todos los casos dio la razón a los reclamantes y consignó en el presupuesto las cantidades demandadas. El total de estos incrementos ascendió a $12.579,25$ pesetas. $^{48}$ Menos fortuna tuvo en su reclamación Mercedes Serrano, maestra del barrio de Villamayor, que demandaba la indemnización por vivienda que le adeudaba el Ayuntamiento desde su toma de posesión, a excepción de tres meses que sí que le habían abonado. En su reclamación también informaba de la intención del Ayuntamiento de hacerla vivir en una casa alquilada por la propia corporación en la localidad donde desarrollaba su actividad profesional, pretensión que la docente rechazaba al tiempo que solicitaba el cobro de la correspondiente indemnización. Al contrario que lo ocurrido con las reivindicaciones precedentes, esta no tuvo respuesta por parte del municipio. ${ }^{49}$ La resolu-

\footnotetext{
48 «Delegado H. ${ }^{a}$ remite reclamación contra el presupuesto de Ascensión Villaba», 1936, Propios y presupuestos, Presupuestos, caja 2533, expediente 141, A.M.Z.; «Delegado H. ${ }^{a}$ remite reclamación contra el presupuesto de Manuel Sancho Ramo», 1936, Propios y presupuestos, Presupuestos, caja 2533, expediente 199, A.M.Z.; «Delegado H. ${ }^{a}$ remite reclamación contra el presupuesto de Lucía Escuder», 1936, Propios y presupuestos, Presupuestos, caja 2533, expediente 253, A.M.Z.; «Delegado H. ${ }^{a}$ remite reclamación contra el presupuesto de Pilar Iglesias», 1936, Propios y presupuestos, Presupuestos, caja 2533, expediente 255, A.M.Z.; «Delegado H. ${ }^{\text {a }}$ remite reclamación contra el presupuesto de Victoriano Sanclemente», 1936, Propios y presupuestos, Presupuestos, caja 2533, expediente 256, A.M.Z.; «Delegado H. ${ }^{\text {a }}$ remite reclamación contra el presupuesto de Bernardina Arantegui», 1936, Propios y presupuestos, Presupuestos, caja 2533, expediente 257, A.M.Z.; «Delegado H. ${ }^{a}$ remite reclamación contra el presupuesto de Catalina Sánchez», 1936, Propios y presupuestos, Presupuestos, caja 2533, expediente 258, A.M.Z.; «Delegado de Hacienda remite reclamación contra el presupuesto de Pedro Tobeñas», 1936, Propios y presupuestos, Presupuestos, caja 2533, expediente 818, A.M.Z.; «Delegado de Hacienda remite reclamación contra el presupuesto de Juan Alcalde Alcalde», 1936, Propios y presupuestos, Presupuestos, caja 2533, expediente 822, A.M.Z.; y «Delegado de Hacienda remite reclamación contra el presupuesto de Juan Jiménez Clavería», 1936, Propios y presupuestos, Presupuestos, caja 2533, expediente 825, A.M.Z.

49 "Consejo $1 .^{\text {a }}$ enseñanza recuerda obligación de pagar subvención por vivienda a la maestra D. ${ }^{a}$ Mercedes Serrano», 1936, Sección de Gobernación, Edificios escolares, caja 3410, expediente 249, A.M.Z.
} 
ción de otras solicitudes se dilató más en el tiempo y fue el Consistorio formado en marzo 1936 el encargado de hacer frente a ellas.

La acción municipal durante el segundo bienio republicano también estuvo encaminada a plantear alternativas al problema. El objetivo que se plantearon los ediles, desde los primeros meses de 1934, fue la búsqueda de alternativas para atajar un gasto que desde comienzos de la República aumentaba cada año y mermaba las posibilidades económicas de la maltrecha hacienda local. Las cifras al respecto eran claras, la partida presupuestaria para el pago de casa-habitación en 1932 había sido de 128.500 pesetas, ascendiendo a 214.800 en 1993 y alcanzando las 219.800 en 1934. En dos años casi se había tenido que duplicar el presupuesto de esta partida. El aumento de este gasto era una consecuencia directa de la reforma educativa puesta en marcha por el gabinete republicano. Uno de los grandes ejes de esta reforma fue la creación de nuevos centros educativos. En Zaragoza fueron puestos en funcionamiento no menos de treinta y cinco centros unitarios, dos escuelas graduadas y otras dos de párvulos, lo que generó la necesidad de contratar nuevos docentes y proporcionarles los alojamientos correspondientes. Los maestros de la periferia también engrosaron los gastos al serles equiparados los emolumentos por casa-habitación hasta las mil quinientas pesetas que percibían sus homólogos del casco urbano. Por último, y aunque en menor medida, la sustitución de la enseñanza religiosa también contribuyó al aumento del coste. Sirva como ejemplo el colegio que los Padres Jesuitas tenían en el centro de la ciudad, que tras ser incautado fue destinado a Instituto de Segunda Enseñanza haciendo necesaria la incorporación de nuevos maestros. La paralización del proceso de sustitución de la enseñanza religiosa durante el segundo bienio evitó un nuevo aumento.

A lo largo del segundo bienio continuó explorándose la posibilidad de ofertar a los maestros viviendas dignas en vez de tener que abonar la correspondiente indemnización. Fueron los republicanos Jenaro Sánchez Remiro, Luís Orensanz y Joaquín Uriarte, en unión de los socialistas Eduardo Castillo y Bernardo Rubio, quienes plantearon una alternativa en el caso de los maestros del interior de la ciudad. Su propuesta estaba basaba en destinar las sesenta mil pesetas sobrantes del último presupuesto extraordinario concertado por el Consistorio para construir viviendas. Sus destinatarios serían aquellos docentes que ve- 
nían percibiendo las mil quinientas pesetas anuales. La propuesta quedaría completada, previo el asesoramiento del Interventor Municipal de fondos, con la habilitación de un crédito suficiente para proceder a la construcción de tres grupos de viviendas, capaces y decentes. Los emplazamientos para dichas construcciones serían las escuelas de Joaquín Costa, Miguel Cervantes y las ubicadas en el barrio de las Delicias. La proposición obtuvo el consenso del pleno municipal, aunque recibió el revés del Interventor Municipal. En su intervención informó que la cuantía de la que podían disponer no era de sesenta mil pesetas sino tan sólo de diecinueve mil. Era abril de 1934 y el proyecto quedó, de momento, paralizado. ${ }^{50}$ La Municipalidad continuó sondeando nuevas alternativas, siendo el arriendo de casas una de ellas. Esta opción fue puesta en marcha en el barrio de Monzalbarba donde la Alcaldía zaragozana, por medio de un bando, solicitó a los vecinos de dicha barriada que ofrecieran las casas que tuvieran desocupadas. Fruto de esta campaña, el cabildo consiguió arrendar cuatro viviendas a precios económicos que posteriormente ofreció a los maestros que en el citado barrio venían desarrollando su actividad. ${ }^{51}$

La opción de construir viviendas volvió a ser retomada un año después, aunque en esta ocasión fue Jenaro Sánchez en solitario quien relanzó el proyecto. En esta ocasión la proposición iba destinada a solucionar el problema en los barrios rurales. Como defendía en su escrito, la construcción de edificios y rentas era inferior en estos barrios y sin embargo la indemnización que debía pagarse a los maestros era la misma que a los del casco de la ciudad. El edil republicano planteaba como una buena operación para las arcas municipales realizar las construcciones en los barrios rurales, pues calculaba que en un periodo de cuatro años podría amortizarse el gasto inicial. En la práctica su propuesta se concretaba en la habilitación, lo más rápido posible, de un empréstito de cincuenta mil pesetas cuyo objetivo sería la construcción de edificios para casa-habitación para los cuatro maestros del barrio de Casetas, uno en Miralbueno y cuatro más en la escuela de Jimeno Rodrigo. Además, en este último emplazamiento, podrían utilizarse los ci-

\footnotetext{
50 «Moción sobre construcción de viviendas para maestros», 1934, Sección de Gobernación, Personal de instrucción, Caja 3391, expediente 1431, A.M.Z.

51 «Arriendo de locales para casa-habitación de maestros en los barrios», 1934, Sección de Gobernación, Personal de instrucción, caja 3391, expediente 1985, A.M.Z.
} 
mientos que ya habían sido construidos y en los que se habían invertido tres mil pesetas. Como ya había ocurrido anteriormente, el proyecto obtuvo el visto bueno de la Municipalidad y la Comisión de Gobernación fue la encargada de estudiar durante varios meses la viabilidad de la operación, dando a conocer en agosto su resolución.

De gran envergadura fue la propuesta que presentó la Comisión de Gobernación. El objetivo era proceder a la construcción de ciento ochenta y tres viviendas destinadas a alojar a docentes tanto del interior de la ciudad como de los barrios de la periferia. Para llevarlo a cabo fue convocado un concurso de proyectos en cuyo pliego de condiciones fueron establecidas las características que deberían reunir las viviendas: tener una superficie aproximada de noventa y cinco metros cuadrados, incluyendo patios y servicios anejos; contar con los siguientes departamentos: comedor, cocina, baño, tres dormitorios y cuarto para el servicio. Además, tendrían preferencia las propuestas que tuvieran, como emplazamiento, solares de propiedad municipal.

Hecha pública la propuesta municipal, a comienzos de septiembre se reunió la Asociación de Maestros de Zaragoza para proceder a su estudio. La asamblea contó con la presencia de un gran número de maestros, tanto de la capital como de los barrios rurales, que tomaron una serie de acuerdos. En primer lugar, felicitaban a la corporación municipal por el proyecto de construcción de viviendas, ya que esta iniciativa serviría para aliviar en algo la situación angustiosa de gran número de parados. Al mismo tiempo protestaban, enérgica pero respetuosamente, por la forma en que iba a llevarse a cabo la construcción de dichas viviendas, por suponer una desconsideración notaria para el magisterio. En caso de llevar a cabo el proyecto, la intención municipal era que cada bloque albergara a ocho familias, teniendo sólo dos entradas y sin que el edificio pasara de tres pisos. Los maestros exigían que la superficie mínima que debían de tener las casas fuera de ciento diez metros cuadrados, teniendo cuantos dormitorios fueran necesarios, una habitación para las visitas y un despacho. Del mismo modo acordaron que antes de que dieran comienzo las obras de las nuevas viviendas, deberían ser revisados escrupulosamente los edificios destinados a escuelas y viviendas existentes, tanto en el interior de la ciudad como en los barrios periféricos, por no reunir las condiciones de solidez, capacidad e higiene. Estos acuerdos fueron comunicados al Ayuntamiento, sin olvi- 
dar detalles importantes como el precio y el emplazamiento, que serían puntualizados a su debido tiempo. ${ }^{52}$

En el mes de septiembre fue abierto el plazo para presentar las propuestas para realizar las obras. Sin embargo, en diciembre la Comisión de Gobernación se veía en la obligación de comunicar que no había sido presentado ningún proyecto. Jenaro Sánchez hizo uso de la palabra en la sesión plenaria para hacer balance de lo ocurrido; como él mismo expresó, desconocía las causas originarias de tal circunstancia. A pesar de este primer intento fallido, el edil defendía la necesidad de volver a anunciar la subasta de las obras, fijando los solares donde habrían de llevarse a cabo y facultando a los contratistas para que pudieran obtener cuantos beneficios pudieran lograr a su favor por la aplicación de las disposiciones vigentes sobre el paro obrero. El nuevo planteamiento tuvo una acogida favorable y se acordó conceder amplia libertad a los promotores para que señalaran las fórmulas económicas para el pago de las construcciones. A comienzos de 1936 volvió a convocarse un segundo concurso para realizar las obras y a esta nueva convocatoria fueron presentadas dos proposiciones. ${ }^{53}$

\section{El Frente Popular. La herencia de cinco años de República}

El triunfo de la candidatura del Frente Popular en las elecciones de febrero de 1936 trajo, entre otras muchas cosas, el acuerdo de reponer los ayuntamientos de elección popular. En Zaragoza el gobernador civil interino, Mariano Menor, fue el encargado de ordenar el cese de los ediles gubernativos y la reposición de aquellos que habían sido elegidos por el pueblo en abril de 1931. Esta medida supuso la vuelta a la alcaldía de Federico Martínez Andrés, destituido por el Gobernador Civil en noviembre de $1933 .{ }^{54} \mathrm{El}$ nuevo equipo directivo fue el encargado de hacer frente, por un lado, a las reclamaciones de los profesores, y por otro,

\footnotetext{
52 «Acuerdos de la Asociación de Maestros de Zaragoza sobre la casa-habitación», La Voz de Aragón (Zaragoza), 3 de septiembre de 1935.

53 «Construcción de viviendas para maestros», 1936, Sección de Gobernación, Edificios escolares, Caja 3410, expediente 2978, A.M.Z.

${ }^{54}$ Un análisis de la evolución política del Ayuntamiento de Zaragoza durante la Segunda República lo podemos encontrar en Manuel Ardid Lorés, Propiedad inmobiliaria y actuación municipal en la Zaragoza de la Segunda República (Zaragoza: Institución Fernando El Católico, 1996), 87-100.
} 
de encontrar la mejor solución al problema de la construcción de las viviendas para los maestros.

En la segunda sesión que celebraba el recién repuesto consistorio, el 20 de marzo de 1936, llegó la resolución del Delegado de Hacienda con respecto al presupuesto municipal aprobado. Habían sido aprobadas todas las partidas a excepción de la destinada al pago de casa-habitación de los maestros. Los rectores municipales del segundo bienio habían conseguido resolver algunos casos, pero todavía quedaban otros pendientes. Rápida resolución tuvieron las reclamaciones interpuestas por María Jesús Rada y Benigna E. Cano. La primera de las reclamantes demandaba el abono de los nueve meses de indemnización que la Municipalidad le adeudaba. Estudiada la reclamación por parte de la Comisión de Gobernación, acordaba consignar el importe de la deuda en el presupuesto de 1937. En el segundo caso, no fue posible el acuerdo puesto que Benigna Cano solicitó seguir disfrutando de la subvención de mil quinientas pesetas y el Ayuntamiento le ofrecía casa en el grupo escolar donde trabajaba. Finalmente el cabildo rechazó la instancia de la maestra. ${ }^{55}$

Mayores dificultades existieron para solucionar las resoluciones adoptadas tanto por la Dirección General de primera Enseñanza como por la Delegación de Hacienda. Los maestros de Casetas, Clemente Mateo y Ladislao Jiménez, al tomar posesión de sus destinos pasaron a percibir la indemnización por casa-habitación. Posteriormente, la Alcaldía trató de facilitar a ambos docentes unas viviendas que había conseguido arrendar en el barrio donde llevaban a cabo su labor. Sin embargo, la Dirección General de Primera Enseñanza resolvió que, al no ser de propiedad municipal las viviendas, los maestros podían no aceptarlas y seguir recibiendo las mil quinientas pesetas anuales. ${ }^{56}$

El Delegado de Hacienda era el encargado de hacer llegar al pleno municipal la reclamación interpuesta contra el presupuesto por un grupo de dieciséis maestros consortes. La demanda venía motivada por la no inclu-

\footnotetext{
${ }_{55}$ «M. ${ }^{a}$ de Jesús Díaz de Rada solicita abono por casa-habitación», 1936, Sección de Gobernación, Edificios escolares, caja 3410, expediente 1858, A.M.Z., y «Benigna E. Cano Maestra de "Ramón y Cajal" renuncia a la vivienda», 1936, Sección de Gobernación, Edificios escolares, caja 3410, expediente 2037, A.M.Z.

56 «Fallo de la Dirección Gral. de 1. ${ }^{a}$ Enseñanza sobre la casa-habitación a los maestros de Casetas Clemente Mateo y Ladislao Jiménez», 1936, Sección de Gobernación, Edificios escolares, caja 3410, expediente 1211, A.M.Z.
} 
sión de la cantidad de mil quinientas pesetas que les correspondía como indemnización por casa-habitación en su calidad de maestros consortes, así como las cantidades que por atrasos se les adeudaban por el mismo concepto. Para sustentar su solicitud esgrimieron una serie de acuerdos municipales y preceptos legales que así lo reconocían. La Alcaldía en respuesta argumentaba que la no consignación de las citadas cantidades no se debía a una omisión, sino sencillamente a que no estaba obligado por precepto legal ni otro título legítimo. Defendía que el principal soporte jurídico en que se apoyaban los maestros consortes era el Decreto de 5 de febrero de 1931 que, sin embargo, había quedado anulado por otro del 22 de agosto del mismo año. La posición municipal venía marcada por la Ley de 1857 y el Estatuto de Magisterio y la Orden de 29 de abril de 1935. El primero establecía la obligación de proporciona a los maestros casa decente y capaz para sí y para su familia. El segundo limitaba el disfrute a una sola casa o una indemnización a los consortes que hubieran contraído matrimonio después de la publicación del mismo. Acogiéndose a esta legislación fueron desestimadas las reclamaciones de los maestros consortes. Ante los argumentos de ambos bandos contendientes, el Delegado de Hacienda estimó la reclamación de los maestros consortes. ${ }^{57}$ Contra ambas reclamaciones, tanto la realizada por la Dirección General de Primera Enseñanza como la admitida a trámite por el Delegado de Hacienda, el Ayuntamiento de Zaragoza planteó sendos recursos de alzada ante el Tribunal provincial de lo contencioso administrativo.

Paralelo a la batalla judicial fue desarrollándose el proyecto de la construcción de viviendas. En poder de la Comisión de Gobernación había dos propuestas sobre las que tenía que resolver y, previo el informe del Interventor de fondos y el Arquitecto de la Corporación, se optó por adjudicar provisionalmente las obras de construcción a Mariano Cebrián. Como ya había ocurrido en septiembre de 1935, los colectivos de maestros volvieron a reunirse para emitir su opinión sobre los proyectos municipales.

La Asamblea de Magisterio de la capital se reunió el 29 de marzo con el objetivo de debatir sobre las viviendas que iban a construirse por parte

\footnotetext{
${ }^{57}$ «Delegado H. ${ }^{a}$ remite reclamación contra el presupuesto de Joaquín Ibáñez y otros Maestros Nacionales (y demás maestros consortes)», 1936, Sección de Propios y presupuestos, Presupuestos, caja 2533, expediente 254, A.M.Z.
} 
del municipio. Queriendo darle un giro al asunto y relacionarlo con el problema del paro obrero, algunos representantes sindicales fueron invitados a participar en la reunión. Ésta tuvo lugar en el grupo escolar Ramón y Cajal y estuvieron presentes dos representantes del Sindicato de la Construcción de la CNT. Idéntica invitación fue cursada a la UGT, aunque del sindicato socialista no hubo ningún representante. Tras debatir ampliamente, el magisterio zaragozano redactó las siguientes conclusiones: primeramente veían con agrado las gestiones realizadas por el Ayuntamiento conducentes a resolver el paro obrero de Zaragoza. Si bien no se oponían al proyecto de construcción de viviendas, rechazaban, sin embargo, la propuesta municipal y pedían que las viviendas fueran instaladas en lugares adecuados y situados en las inmediaciones de los grupos escolares. Las viviendas deberían ser todas iguales y de una mayor amplitud para que pudieran ser habitadas por la generalidad de los maestros. Deberían ser amortizables en un plazo prudencial con las consignaciones que para casa-habitación recibía cada maestro. Para poder solucionar el urgente problema del paro obrero, pedían que comenzaran las obras de construcción de casas baratas para obreros y clase media, así como los locales para escuelas que fueran necesarios para llevar a cabo la sustitución de la enseñanza religiosa. Aprovechando las vacaciones de Semana Santa pedían que fueran verificadas en todas las escuelas las obras de reparación, blanqueo y pintura que fueran necesarias. ${ }^{58}$

Aunque todas las partes implicadas mostraron buena predisposición para solucionar el problema, no consiguieron alcanzar un acuerdo satisfactorio. Fue el socialista Bernardo Rubio, destacando el estado de apasionamiento que había tomado el asunto, quien propuso celebrar una reunión extraordinaria. En ella estarían presentes los integrantes de la Comisión de Gobernación, una Comisión de maestros, representantes de la Confederación Nacional de Trabajo y la Unión General de Trabajadores, un Arquitecto municipal y los Letrados Asesores. La finalidad de la asamblea sería estudiar el asunto armónicamente, sin perjudicar los intereses de la corporación. En la misma sesión municipal la Comisión de Gobernación informó que finalmente la propuesta de Mariano Cebrián había sido rechazada. Como alternativa planteó la posibilidad

\footnotetext{
58 «Proyectos realizados - Asamblea del Magisterio de la capital para tratar de las viviendas que quiere construirle el Ayuntamiento», Diario de Aragón (Zaragoza), 31 de marzo de 1936, y «La casa-vivienda para los maestros», Heraldo de Aragón (Zaragoza), 31 de marzo de 1936.
} 
de que fueran los propios arquitectos municipales los que redactaran el proyecto y que el Interventor de Fondos planteara el procedimiento más beneficioso para habilitar los créditos necesarios..$^{59}$

La reunión extraordinaria tuvo lugar la mañana del seis de abril de 1936 y en ella estuvieron presentes los integrantes de la Comisión de Gobernación junto con los técnicos de la casa, el letrado asesor Isábal, una representación de la Asociación de Magisterio y representantes de las centrales sindicales socialista y anarquista. La reunión no tuvo carácter público, por lo que las únicas referencias que tenemos de ella son las que publicó la prensa. El letrado Isábal, a fin de beneficiar los intereses del erario público, pidió que la adjudicación se realizara por medio de subasta y no de concurso. Los técnicos arquitectos pusieron reparos a los proyectos de viviendas confeccionados y se mostraron favorables a la opinión expresada por Isábal; al mismo tiempo urgían a no demorar la realización del proyecto en más de un mes. Los maestros afirmaron que en su ánimo no estaba el poner trabas al Ayuntamiento; por último, los representantes de la Unión General de Trabajadores y Central Nacional de Trabajadores exhortaron al Ayuntamiento a que tomara las garantías necesarias compatibles con las aspiraciones del magisterio, indicando, de igual modo, que no tolerarían que se torpedearan proyectos que pudieran dar trabajo a la clase obrera. Una vez que todos los implicados habían puesto en común sus impresiones, la Comisión de Gobernación las recogió y quedó encargada de formular un dictamen que sometería a la aprobación del Ayuntamiento. ${ }^{60}$

En las postrimerías de mayo, la Dirección de Arquitectura había redactado ya el primer proyecto de viviendas. Incluía la construcción de cuatro edificios de iguales características emplazados en la carretera de Valencia, cuyo coste ascendía a 1.161.890,76 pesetas. Las casas tendrían las siguientes características: la forma de la planta sería rectangular dando así lugar a un sistema lineal a lo largo de un pasillo central; dos de las casas dispuestas contiguamente tendrían su fachada orientada a la carretera de Valencia y otras dos, de igual modo, a otra calle

\footnotetext{
59 "Actas del Ayuntamiento de Zaragoza», 3 de abril de 1936, A.M.Z.

${ }^{60}$ «La casa-habitación. Se ha celebrado la anunciada reunión extraordinaria para tratar de este asunto», Heraldo de Aragón (Zaragoza), 7 de abril de 1936, y «La construcción de viviendas para maestros», El Noticiero (Zaragoza), 7 de abril de 1936.
} 
de nueva formación, y entre ambas habría un gran patio colectivo; el número de viviendas por bloque sería de ocho, en cuatro plantas y una de áticos para uso de un portero. En esta planta también se dispondría de cuartos trastero con la debida amplitud. La superficie construida por planta sería de 263,30 metros cuadros, correspondiendo 131,15 metros cuadrados por vivienda. Cada casa estaría compuesta por comedor, cocina, baño y siete departamentos, todos ellos con las dimensiones y cubicaciones que exigía le ley vigente de casas baratas. Para hacer frente a la inversión de las obras sería necesario formalizar un empréstito con la garantía de la cuantía que se satisfacía por casa-habitación. La intención era anunciar en un plazo lo más breve posible la subasta para remediar el paro obrero. ${ }^{61}$ Cuando se dio a conocer en el salón de plenos ningún edil se opuso al proyecto. ${ }^{62}$

Una semana después la Comisión de Gobernación hizo público el segundo proyecto realizado por la Dirección de Arquitectura. La propuesta incluía la construcción de dieciséis viviendas emplazas en el jardín del grupo escolar Jimeno Rodrigo. El presupuesto total de la obra ascendería a 578.297,48 pesetas y el modo de sufragar el gasto sería el mismo que en el caso anterior: formalizar un empréstito con la garantía de lo que el municipio satisfacía por casa-habitación a los maestros. Tras darse a conocer el proyecto y sus cifras, el edil del Partido Radical Ángel Marco mostró su oposición argumentado que era antieconómico para los intereses de la municipalidad. ${ }^{63}$ La documentación volvió a la Dirección de Arquitectura que se encargó de desglosar las cifras. Cada vivienda suponía un coste anual superior a las mil ochocientas pesetas, rebasando las mil quinientas pesetas que tenía intención de destinar el Ayuntamiento. Con todos estos datos, la Comisión de Gobernación propuso la formalización de un empréstito de tres millones de pesetas para llevar a cabo la construcción de las viviendas, ofreciendo como garantía la cantidad que para subvención por casa-habitación figuraba en los presupuestos municipales. ${ }^{64}$

\footnotetext{
${ }^{61}$ «Construcción de viviendas para maestros», 1936, Sección de Gobernación, Edificios escolares, Caja 3410, expediente 2978/1936, A.M.Z.

62 "Actas del Ayuntamiento de Zaragoza», 22 de mayo de 1936, A.M.Z.

63 «Actas del Ayuntamiento de Zaragoza», 29 de mayo de 1936, A.M.Z.

${ }^{64}$ «Dictamen proponiendo formalización de un empréstito para construir viviendas de maestros», 1936, Sección de Gobernación, Edificios escolares, Caja 3410, expediente 3366, A.M.Z.
} 
La búsqueda de soluciones para alojar a los maestros no implicó que los ayuntamientos dejaran de insistir al Gobierno para que se hiciera cargo de esta atención. Y esto quedó patente en junio de 1935 cuando la alcaldía de Cartagena propuso que todas las alcaldías españolas solicitaran al Gobierno que en los siguientes presupuestos generales consignaran la cantidad suficiente para atender esta obligación..$^{65} \mathrm{El}$ golpe de Estado y la subsiguiente guerra civil supusieron la destitución de las autoridades republicanas de Zaragoza y el fin del proyecto para dotar a los maestros de viviendas.

\section{CONCLUSIONES}

La Ley de Instrucción Pública de 9 de septiembre de 1857 fijaba por primera vez el derecho de los maestros a disfrutar de una casa decente y capaz que debían sufragar los ayuntamientos de las poblaciones donde ejercían su magisterio. En torno a la interpretación de este derecho, que quedó recogido en el artículo 191 de le citada Ley, fue desarrollándose una profusa legislación que afectó, principalmente, a los maestros consortes. La falta de concreción del precepto legislativo motivó que en unas ocasiones fuera interpretado en sentido amplio y en otras de forma restrictiva. Y en éste último sentido lo interpretó la Orden de junio de 1870 que estableció que los maestros consortes sólo tuvieran derecho a una casa o una indemnización. Posteriormente fueron publicadas las Real orden de junio de 1910 y el Real decreto de septiembre de 1913 que plantearon una aplicación del derecho en sentido restrictivo, y la Real orden de junio de 1911 que defendía el derecho de los maestros consortes a disfrutar del derecho del mismo modo que los no consortes. Con el objetivo de acabar con las dudas que habían surgido a lo largo de los años en la interpretación del artículo 191, fue promulgado el Real decreto de febrero de 1919 donde quedaban equiparados los derechos de los maestros consortes y de los no consortes. La nitidez de la norma no impidió que los redactores del Estatuto General del Magisterio de Primera Enseñanza volvieran a establecer modificaciones, restringiendo el derecho de los maestros consortes a una casa o indemnización. Este Estatuto permaneció inalterado

\footnotetext{
${ }_{65}$ «Alcaldía de Cartagena invita al Ayuntamiento a solicitar de los Poderes públicos no sea obligación el pago de casa a los maestros», 1936, Sección de Gobernación, Edificios escolares, caja 3410, expediente 3467, A.M.Z.
} 
hasta febrero de 1931 cuando, con Dámaso Berenguer en el poder, volvió a serle reconocido a los maestros consortes el derecho en el sentido más amplio. Sin embargo, tras el ascenso al gobierno del Almirante Aznar, volvió a ser repuesto el Estatuto General del Magisterio de Primera Enseñanza volviéndose a restringir el derecho de los maestros consortes.

Tras la proclamación de la República, los nuevos dirigentes no demoraron mucho la decisión de conceder a los maestros consortes por duplicado dicho derecho. El Ayuntamiento de Zaragoza también les concedería el mismo derecho y durante algunos años no habría conflicto alguno. Sin embargo, la Orden de primero de agosto de 1934, reduciendo el derecho a una casa-habitación o una indemnización a los maestros consortes reabría nuevamente el problema. El cabildo zaragozano aplicó esta medida a los maestros consortes. lo que generó un aluvión de reclamaciones. Cuando el Gobierno, un año después, volvió a reconocer el pleno derecho de los maestros consortes, los ediles zaragozanos también tuvieron que acatarlo. Aún así, la Alcaldía pidió que el acuerdo fuera declarado lesivo y finalmente el Tribunal Contencioso reconocía que los maestros consortes que residieran en la misma población solo tenían derecho a una casa-habitación o indemnización.

A lo largo del quinquenio republicano el ente municipal zaragozano trató de buscar soluciones a una obligación que cada vez le resultaba más onerosa económicamente. Durante el primer bienio ofreció a los maestros algunas de las viviendas que el municipio había tenido que adquirir en la zona de ensanche tras la quiebra de la empresa que estaba gestionando las obras. Durante el segundo bienio fueron dos las medidas que trató de poner en marcha el Ayuntamiento para reducir el impacto económico que le suponía la indemnización por casa-habitación. En algunos barrios de la ciudad consiguió arrendar viviendas a un coste inferior que posteriormente ofreció a los maestros que trabajaban en dichos barrios. Pero el proyecto más ambicioso fue el que intentaron poner en marcha los ediles en 1936. Consistía en construir edificios para destinarlos a viviendas de los maestros consiguiendo un beneficio tanto para el Ayuntamiento, en el plano económico, como para los maestros, que podrían acceder a la propiedad de una vivienda de forma cómoda. Sin embargo, todos estos proyectos quedaron en meras intenciones cuando el golpe de Estado trajo consigo la destitución de las autoridades republicanas en Zaragoza. 


\section{Nota sobre el autor}

Héctor Vicente Sánchez es doctorando del Departamento de Historia Moderna y Contemporánea de la Universidad de Zaragoza. Su Tesis doctoral versó sobre «El Ayuntamiento de Zaragoza durante la Segunda República. Gobierno, administración y gestión municipal». Como avance de esta línea de investigación ha publicado algunos trabajos en revistas y actas de congresos, entre los que se pueden destacar: "Sebastián Banzo Urrea. (1883-1956). Primer alcalde de la II República», Rolde. Revista de Cultura aragonesa, 148-150 (2014): 46-59; "Los Ayuntamientos del Frente Popular», en La Historia, lost in translation? Actas del XIII Congreso de la Asociación de Historia Contemporánea, coords. Damián González, Manuel Ortiz y Juan Sisinio Pérez Garzón (Castilla-La Mancha, Ediciones de la Universidad de Castilla-La Mancha, 2017), 1653-1708, y «La secularización de la enseñanza primaria durante la Segunda República», Historia de la educación. Revista interuniversitaria, 36 (2017): 301-320. La segunda línea de investigación que está abordando es sobre la represión de la masonería en Zaragoza, estando pendientes de publicación sendos trabajos en las actas del XI Congreso de Historia Local de Aragón y la Revista de Estudios Históricos de Masonería.

\section{REFERENCIAS}

Ardid Lorés, Manuel. Propiedad inmobiliaria y actuación municipal en la Zaragoza de la Segunda República. Zaragoza: Institución Fernando El Católico, 1996.

Gómez Fernández, Juan. La escuela pública en el Puerto: entre la ilusión y la represión. El Puerto de Santa María (Cádiz): El Boletín, 2015.

González Pérez, Jesús. «La indemnización por casa-habitación y la contribución de utilidades». Revista de Administración Pública 18 (1955): 207-220.

Terrón, Aida. «El movimiento asociacionista del magisterio nacional: orígenes y configuración histórica». Historia de la Educación. Revista interuniversitaria 6 (1987): 279-300.

Terrón, Aida. «Cien años de defensa colectiva: la dinámica societaria y sindical del magisterio español». Sarmiento. Anuario galego de historia da educación 3 (1999): 157-182. 